Published in final edited form as:

Lai, F., Feng, J., Heil, T., Wang, G.-C., Adler, P., Antonietti, M., et al. (2019). Strong metal oxide-support interactions in carbon/hematite nanohybrids activate novel energy storage modes for ionic liquid-based supercapacitors. Energy Storage Materials, 20, 188-195. doi:10.1016/j.ensm.2019.04.035.

\title{
Strong metal oxide-support interactions in carbon/hematite nanohybrids activate novel energy storage modes for ionic liquid-based supercapacitors
}

Feili Lai, Jianrui Feng, Tobias Heil, Gui-Chang Wang, Peter Adler, Markus Antonietti, Martin Oschatz

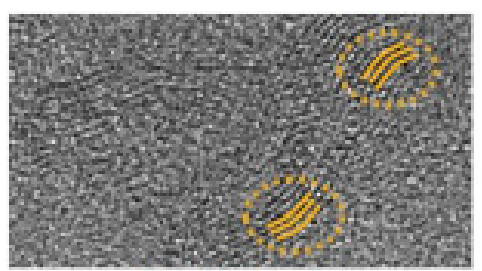

Subtle atomic

arrangement distortion
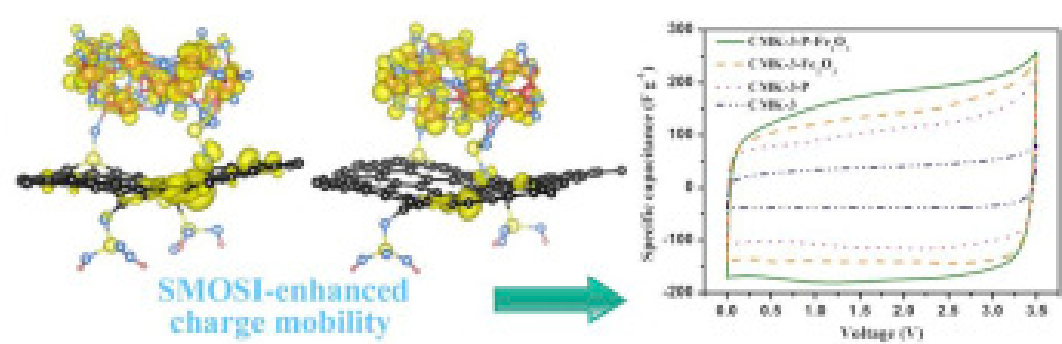

Strong metal-oxide-support interaction is created between $\alpha-\mathrm{Fe} 2 \mathrm{O} 3$ and phosphorus-doped mesoporous carbon (CMK-3-P) support. Intimate contact between the phases leads to enhanced adsorption of ionic liquid ions and thus higher energy storage performance in supercapacitors if compared to oxide-free materials with even higher porosity. 


\title{
Strong metal oxide-support interactions in carbon/hematite nanohybrids activate novel energy storage modes for ionic liquid-based supercapacitors
}

\begin{abstract}
Strong metal oxide-support interaction is crucial to activate high energy storage modes of carbon-supported hybrid electrodes in ionic liquid-based supercapacitors. Although it is known that conductive supports can influence the electrochemical properties of metal oxides, insights into how metal oxide-support interactions can be exploited to optimize joint energy storage properties are lacking. We report the junction between $\alpha-\mathrm{Fe}_{2} \mathrm{O}_{3}$ nanosplotches and phosphorus-doped ordered mesoporous carbon (CMK-3-P) with strong covalent anchoring of the metal oxide. The oxide-carbon interaction in $\mathrm{CMK}-3-\mathrm{P}-\mathrm{Fe}_{2} \mathrm{O}_{3}$ is strengthening the junction and charge transfer between $\mathrm{Fe}_{2} \mathrm{O}_{3}$ and $\mathrm{CMK}-3-\mathrm{P}$. It enhances energy storage by intensifying the interaction between ionic liquid ions and the surface of the electrode. Synergistically, density functional theory simulations reveal that the strong metal oxide-support interaction increases the adsorption energy of ionic liquid to $-4.77 \mathrm{eV}$ as compared to $-3.85 \mathrm{eV}$ for $\mathrm{CMK}-3-\mathrm{Fe}_{2} \mathrm{O}_{3}$ hybrid with physical binding. In spite of the lower specific surface area and apparently similar energy storage mode, the CMK-3-P- $\mathrm{Fe}_{2} \mathrm{O}_{3}$ exhibits superior electrical double-layer capacitor performance with a specific capacitance of $179 \mathrm{~F} \mathrm{~g}^{-1}$ at $2 \mathrm{mV} \mathrm{s}^{-1}(0-3.5 \mathrm{~V})$ in comparison to $\mathrm{Fe}_{2} \mathrm{O}_{3}$-free CMK-3 and CMK-3-P reference materials. This principle for design of hybrid electrodes can be applicable for future rational design of stable metal oxide-support electrodes for advanced energy storage.
\end{abstract}

Keywords: electrocatalysis, supercapacitor, nanohybrid, iron oxide, ionic liquid, ordering transitions

\section{Main text}

Due to their unique characteristics such as high power density and stable cycling life, supercapacitors have received tremendous attention during the past decade. They are considered as a bridge to close the energy and power gap between plate capacitors and batteries. ${ }^{[1-4]}$ Despite the considerable effort that has been made to design effective electrode materials for supercapacitors, their energy density (E) is still limited. ${ }^{[5-9]}$ The E value of a supercapacitor is determined by the specific capacitance $(\mathrm{C})$ and working-voltage window (V), according to $\mathrm{E}=0.5 \times \mathrm{C} \times \mathrm{V}^{2}$. The majority of supercapacitors is based on aqueous electrolytes. Although their voltage window can be extended even beyond the electrochemical potential of water splitting $(1.23 \mathrm{~V})$ it usually remains confined at less than $1.8 \mathrm{~V}^{[10,11]}$ Electrolytes composed of salts in organic solvents can be operated in a wider voltage window and have thus in most cases higher specific energy. ${ }^{[12-15]}$ 
Another class of electrolyte with possibly even larger voltage window are ionic liquids (ILs) which are salts being in liquid phase at room temperature. ${ }^{[16,17]}$ Besides the high electrochemical stability, one of the particular advantages of IL electrolytes is the possible contribution of the bulk of the electrolyte to the energy storage. It has been recently explored that IL ions confined in carbon mesopores are able to undergo ordering transitions in the presence of an electric potential. The enthalpy difference is translated to energy that is stored on top of the regular charge separation by enrichment of counter-ions on electrode surfaces. $^{[18,19]}$ The possibility of such voltage-induced ordering transitions was earlier investigated by Salanne and Rotenberg on metal surfaces ${ }^{[20]}$ and was recently also found in carbon micropores by Futamura et al. ${ }^{[21]}$ In mesopores these transitions occur as a collaborative effect and can thus possibly give an even more significant contribution to energy storage. The size and volume of the mesopores is becoming a crucial factor as apparently the transitions can occur until deep in the bulk of the electrolyte confined in mesopores. ${ }^{[19]}$ However, high potentials are needed to induce the ordering transitions and it remains a major task to avoid material degradation at the electrode/electrolyte interface at the same time. In other words, the traditional energy storage mechanism of a "compression double-layer" as present in solvent-based electrolytes seems to shift to a "structure-transition" double-layer in ILs as a gradient of over-all ion concentration can not exist in such systems and the practical charge storage ability of IL-based supercapacitors is too high to result from charge separation in a double-layer alone. Furthermore, it has been found that the contribution of this effect can be significantly enhanced in the presence of metal oxides on the carbon surface. ${ }^{[22]}$ Redoxtype processes can also contribute in such metal oxide containing systems operated with IL electrolytes ${ }^{[23]}$ but unlike it is typical for aqueous and organic electrolytes, a recent study has unrevealed that IL-based supercapacitors based on heteroatom-doped mesoporous carbon $/ \mathrm{MnO}_{2}$ hybrid electrodes do not show significant pseudocapacitive contributions (i.e., no redox electron transfer between electrolyte and metal oxide surface) due to the high electrochemical stability of ILs. However, the nanojunctions between $\mathrm{MnO}_{2}$ and carbon could serve for strong electrolyte adsorption at the 3-phase boundary between carbon, metal oxide, and electrolyte as indicated by the increased capacity at significantly lower specific surface area and pore volume in comparison to a metal-free electrode material. Heteroatom doping of the carbon matrix was found to be crucial for uniform deposition of $\mathrm{MnO}_{2}$ into its pores. However, the influence of the strength of electronic communication or, in other words, the intimacy of junction between carbon and oxide remained poorly investigated but may play a crucial role for the energy storage properties. 


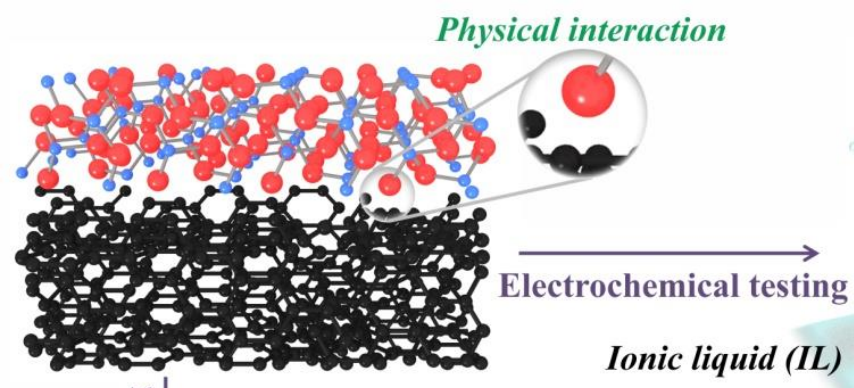

๘

Ionic liquid (IL) Chemical bond

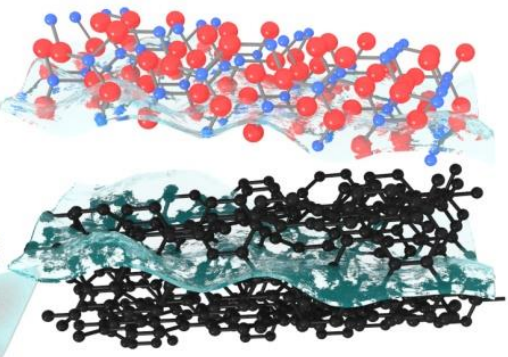

Unstable secondary microstructure Weak metal-oxide-support interactions $X$

Strong metal-oxide-support interactions (SMOSI)
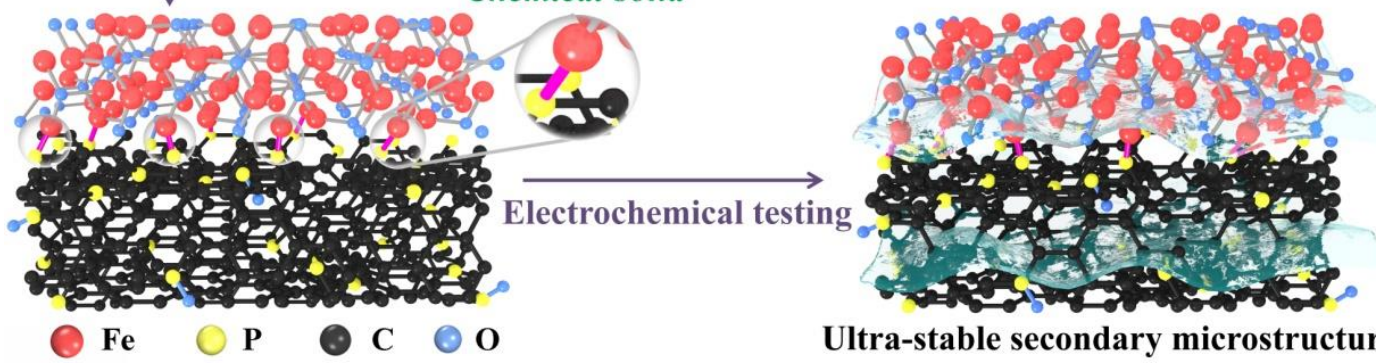

Ultra-stable secondary microstructure

Figure 1 Enhanced electrochemical properties of metal oxide-support hybrid by using surface engineering with formation of strong metal oxide-support interactions (SMOSI) instead of weak metal oxide-support interactions.

One metal oxide that has been widely applied in carbon-composites for electrochemical energy storage (most often for redox-based) charge storage in supercapacitors is iron oxide because of its low cost, natural abundance, and environmental friendliness. ${ }^{[24-28]}$ To overcome the low conductivity and limited specific surface area of bulk $\mathrm{Fe}_{2} \mathrm{O}_{3}$, it has to be deposited on a conductive nanoporous carbon material. Physical immobilization is commonly applied but leads to a weak interaction between carbon and $\mathrm{Fe}_{2} \mathrm{O}_{3}$ (Figure 1) and thus possibly inefficient electron transfer and low stability during electrochemical application. Carbon surface engineering can be an effective solution to construct strong metal oxide-carbon interactions (SMOSIs) by introducing heteroatoms such as phosphorous on the carbon surface. This can lead to the formation of covalent metal-heteroatom bonds and possibly enhances the strength of electronic communication and stability during electrochemical energy storage application. We report a surface engineering process to form phosphorus-doped ordered mesoporous carbon (CMK-3-P), followed by $\mathrm{Fe}_{2} \mathrm{O}_{3}$ deposition to obtain a phosphorus-doped mesoporous carbon- $\alpha-\mathrm{Fe}_{2} \mathrm{O}_{3}\left(\mathrm{CMK}-3-\mathrm{P}-\mathrm{Fe}_{2} \mathrm{O}_{3}\right)$ hybrid with strong metal oxide-carbon interactions. 

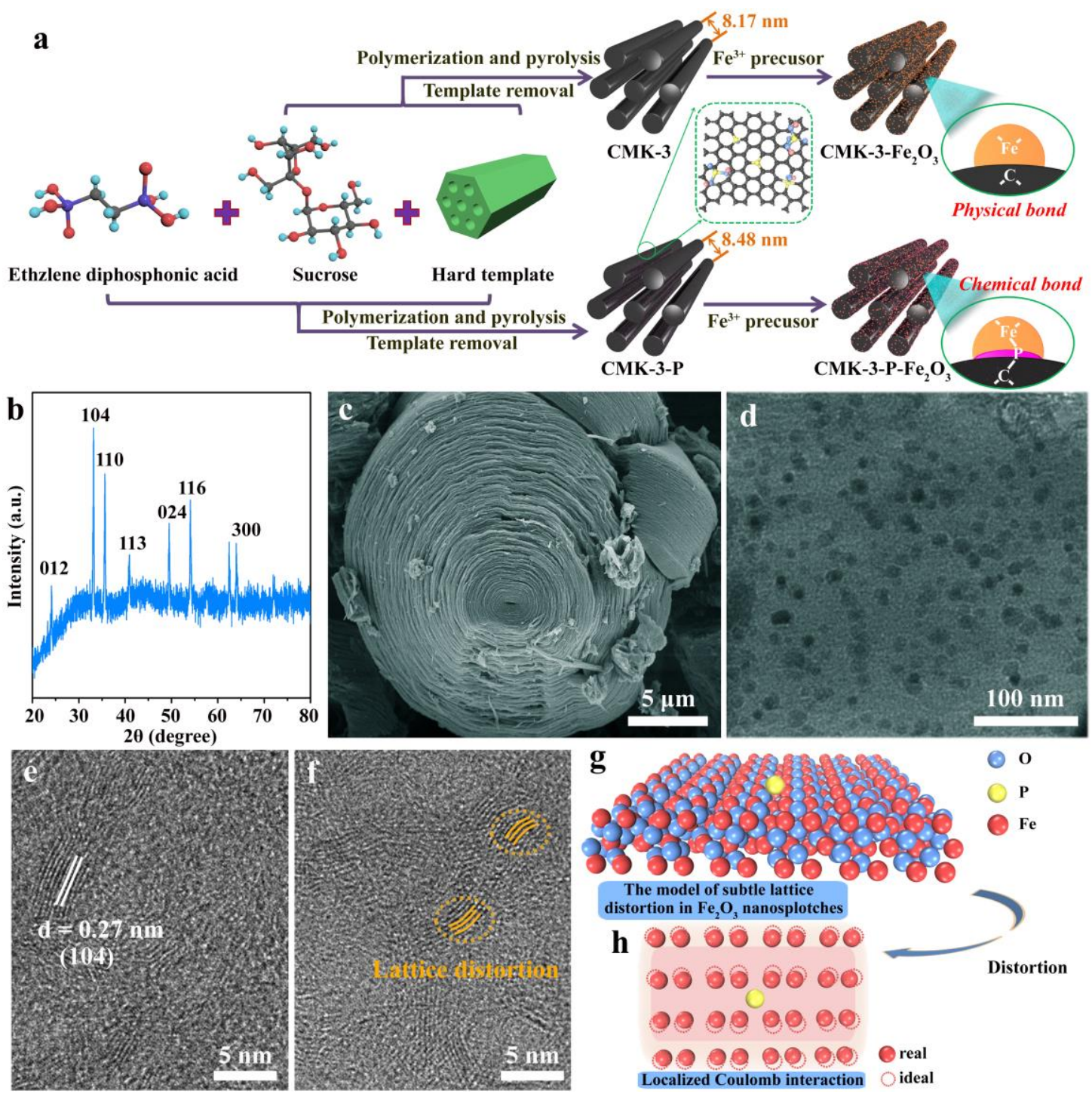

○ 0

P

- $\mathrm{Fe}$

Figure 2 (a) Synthesis process of CMK-3-P- $\mathrm{Fe}_{2} \mathrm{O}_{3}$ and $\mathrm{CMK}-3-\mathrm{Fe}_{2} \mathrm{O}_{3}$ hybrids. (b) XRD pattern, (c) SEM, (d) TEM, and (e, f) HRTEM images of CMK-3-P-Fe $\mathrm{O}_{3}$ hybrid. (g, h) Proposed mechanism for the subtle lattice distortion induced by phosphorus atoms on the surface of carbon support.

As illustrated in Figure 2a, phosphorus-doped mesoporous carbon (CMK-3-P) was fabricated by adding ethylene diphosphonic acid to the ordered mesoporous carbon (CMK-3) as the $\mathrm{P}$ source. ${ }^{[29]}$ The typical uniform and homogeneous ordered mesoporous textures of CMK-3 are also present in CMK-3-P (Figure S1). The mean distance between the carbon nanorods of 8.1 $\mathrm{nm}$ slightly increased as compared to $7.5 \mathrm{~nm}$ in CMK-3 as revealed by the small-angle X-ray scattering (SAXS) measurements (Figure S2). Nitrogen physisorption experiments (Figure S3) suggest uniform pore size distribution of CMK-3-P with both micropores and mesopores comparable to CMK-3. However, addition of ethylene diphosphonic acid to the synthesis 
leads to a slight increase of the content of micropores but a slight decrease of the specific surface area $\left(0.24 \mathrm{~cm}^{3} \mathrm{~g}^{-1}, 1094 \mathrm{~m}^{2} \mathrm{~g}^{-1}\right)$ compared to CMK-3 $\left(0.10 \mathrm{~cm}^{3} \mathrm{~g}^{-1}, 1134 \mathrm{~m}^{2} \mathrm{~g}^{-1}\right)$ (Table S1). At the same time, the mesopore volume of CMK-3-P slightly decreased as compared to CMK-3. Phosphorous doping also leads to enhanced wettability of the surface with 1-ethyl-3-methylimidazolium tetrafluoroborate $\left(\mathrm{EMIMBF}_{4}\right)$ IL compared with the pristine CMK-3 substrate (Figure S4).

As shown in Figure 2b, the X-ray diffraction (XRD) pattern of CMK-3-P- $\mathrm{Fe}_{2} \mathrm{O}_{3}$ hybrid shows several sharp peaks corresponding to the (012), (104), (110), (113), (024), (116), and (300) reflections of hematite $\alpha-\mathrm{Fe}_{2} \mathrm{O}_{3}$ (JCPDS no, 33-0664). This indicates that in addition to $\mathrm{Fe}_{2} \mathrm{O}_{3}$ embedded into the mesopores, some larger particles are formed on the external surface of the CMK-3-P particles as well. The XRD pattern of CMK-3-P- $-\mathrm{Fe}_{2} \mathrm{O}_{3}$ is comparable to that of CMK-3- $-\mathrm{Fe}_{2} \mathrm{O}_{3}$ (Figure S5). Despite $\mathrm{P}$ doping, no additional iron phase is present. In accordance, Mössbauer spectroscopy analysis of both samples also shows that hematite $(\alpha-$ $\mathrm{Fe}_{2} \mathrm{O}_{3}$ ) is the only apparent iron phase independent of the presence or absence of P (Figure S6 and Table S2) and that the $\mathrm{Fe}_{2} \mathrm{O}_{3}$ components in both, CMK-3- $\mathrm{Fe}_{2} \mathrm{O}_{3}$ and $\mathrm{CMK}-3-\mathrm{P}-\mathrm{Fe}_{2} \mathrm{O}_{3}$, behave similar as bulk hematite. The successful loading of large parts of $\mathrm{Fe}_{2} \mathrm{O}_{3}$ into the pore system of the CMK-P support is further demonstrated by scanning electron microscopy (SEM) and transmission electron microscopy (TEM). The phosphorus-doped mesoporous carbons consist of layer-by-layer stacked carbon nanorods, while its outer framework contains only a minor amount of agglomerated $\mathrm{Fe}_{2} \mathrm{O}_{3}$ particles (Figure 2c). Homogeneous distribution of $\mathrm{C}, \mathrm{O}, \mathrm{P}$, and $\mathrm{Fe}$ is proven by energy dispersive X-ray spectroscopy (EDX) elemental mapping of CMK-3-P-Fe $\mathrm{O}_{3}$ (Figure S7). The loading of rather long and non-spherical $\mathrm{Fe}_{2} \mathrm{O}_{3}$ "nanosplotches" (NSes) on the surface of the tubular mesopores of CMK-3-P and CMK-3 are 19 wt.\% and 25 wt.\%, respectively (Figure S8). $\alpha-\mathrm{Fe}_{2} \mathrm{O}_{3}$ NSes with size of 8-16 nm can be observed (Figure 2d) with uniform dispersion. At higher magnification, it can be seen that $\alpha$ $\mathrm{Fe}_{2} \mathrm{O}_{3}$ NSes exhibit a lattice spacing of $0.27 \mathrm{~nm}$, which can be assigned to the (104) direction, in agreement with the XRD results. The defect-rich structure of $\alpha-\mathrm{Fe}_{2} \mathrm{O}_{3}$ is also shown in Figure S9. Meanwhile, some distorted lattice plains of $\alpha-\mathrm{Fe}_{2} \mathrm{O}_{3}$ are observed in HRTEM images of $\mathrm{CMK}-3-\mathrm{P}-\mathrm{Fe}_{2} \mathrm{O}_{3}$ (Figure 2f). We do not find such significant lattice distortion in the $\mathrm{CMK}-3-\mathrm{Fe}_{2} \mathrm{O}_{3}$ hybrid (Figure $\mathrm{S} 10$ ). This difference may be caused by the P-containing groups on the CMK-P support (Figure $2 \mathrm{~g}$ ). As a result, the presence of $\mathrm{P}$ atoms can potentially lead to anion site substitution and thus influence the surface structure of the oxide (Figure $2 \mathrm{~h}$ ), leading to the nanoscale crystal dislocations and distortions of $\alpha-\mathrm{Fe}_{2} \mathrm{O}_{3}$. 

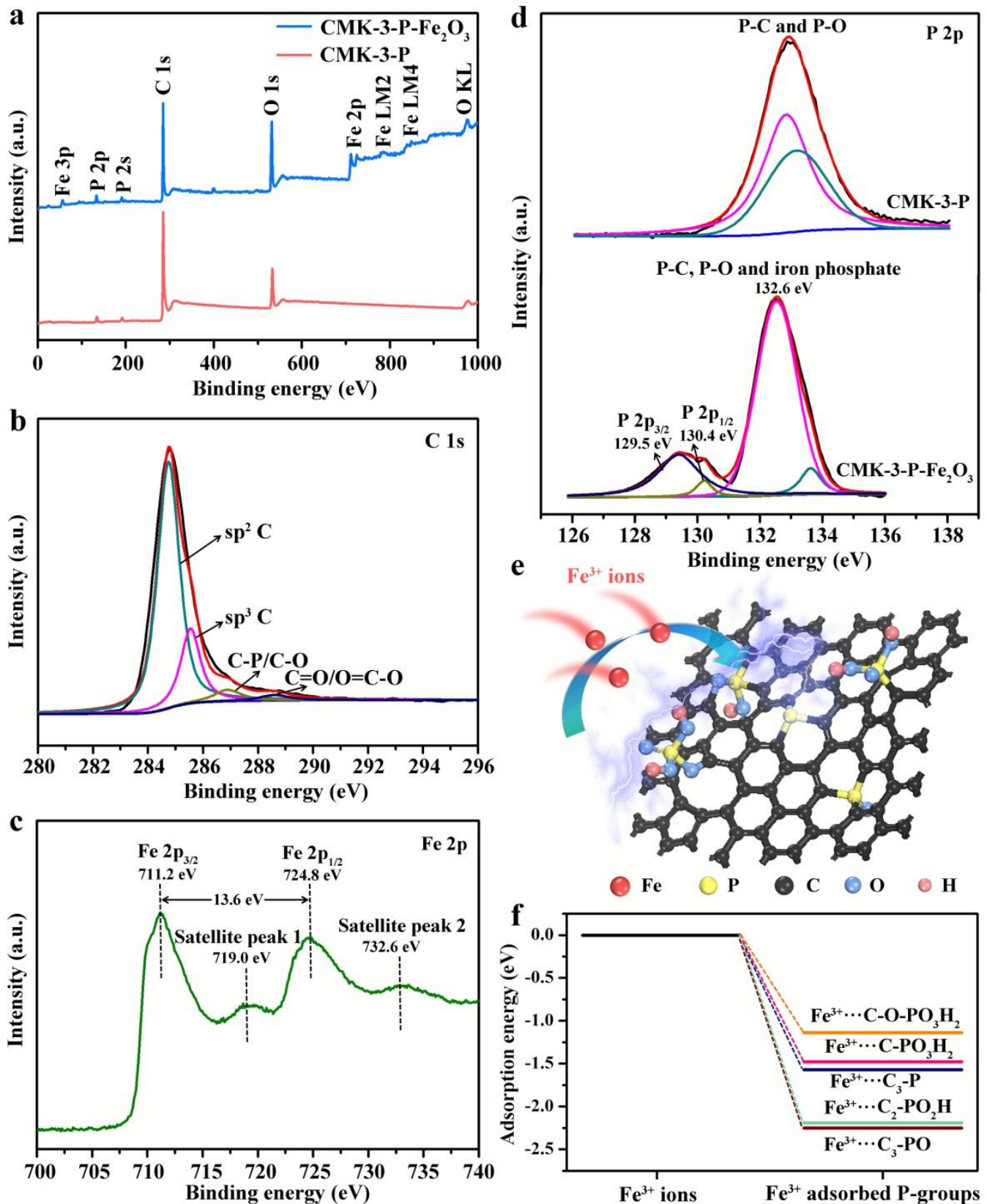

Figure 3. (a) XPS survey spectra of $\mathrm{CMK}-3-\mathrm{P}$ and $\mathrm{CMK}-3-\mathrm{P}-\mathrm{Fe}_{2} \mathrm{O}_{3}$. High resolution spectrum with peak fitting of the (b) C 1s XPS peak and (c) Fe 2p XPS peak of CMK-3-P$\mathrm{Fe}_{2} \mathrm{O}_{3}$ hybrid. (d) High resolution spectra with peak fitting of the P $2 p$ XPS peaks of CMK-3$\mathrm{P}$ and $\mathrm{CMK}-3-\mathrm{P}-\mathrm{Fe}_{2} \mathrm{O}_{3}$. (e) Simulation-based scheme of the reaction process between $\mathrm{Fe}^{3+}$ ions and P-doped atomic carbon configuration. (f) Calculated $\mathrm{Fe}^{3+}$ ion adsorption energy on different P-containing groups.

X-ray photoelectron spectroscopy (XPS) was used to study the surface chemical compositions, valence states, and bonding structures of $\mathrm{CMK}-3-\mathrm{P}-\mathrm{Fe}_{2} \mathrm{O}_{3}$ hybrid. Density functional theory (DFT) calculation was applied to simulate the binding state of $\mathrm{Fe}^{3+}$ on the surface of CMK-3-P support. The XPS survey spectrum of CMK-3-P-Fe $\mathrm{O}_{3}$ hybrid (Figure 
3a) shows the signals of $\mathrm{C}, \mathrm{O}, \mathrm{P}$, and Fe. By comparing with the spectrum of metal-free CMK3-P, the $\mathrm{Fe} 2 \mathrm{p}$ peaks at 711.2 and $724.8 \mathrm{eV}$ are corresponding to $\mathrm{Fe}^{3+}$ species from the $\mathrm{Fe}_{2} \mathrm{O}_{3}$ Nses. ${ }^{[30]}$ The C 1s signal has contributions of four peaks at 284.8, 285.6, 286.9, and $288.6 \mathrm{eV}$, which can be attributed to $\mathrm{sp}^{2}$ bonded carbon, $\mathrm{sp}^{3}$ bonded carbon, C-P/C-O groups, and $\mathrm{C}=\mathrm{O} / \mathrm{O}=\mathrm{C}-\mathrm{O}$ groups, respectively (Figure $3 \mathrm{~b}$ ). ${ }^{[31]} \mathrm{The} \mathrm{sp}^{3}$ carbon density can be reflected by the ratio of basal $\mathrm{sp}^{2}$ to tetrahedral $\mathrm{sp}^{3}$ carbon atoms $\left(\mathrm{sp}^{2} / \mathrm{sp}^{3}\right) .{ }^{[32]}$ Compared to $\mathrm{CMK}-3-\mathrm{Fe}_{2} \mathrm{O}_{3}$ hybrid (Figure $\mathrm{S} 11$ ), the value of $\mathrm{sp}^{2} / \mathrm{sp}^{3}$ for $\mathrm{CMK}-3-\mathrm{P}-\mathrm{Fe}_{2} \mathrm{O}_{3}$ hybrid decreased from 3.98 to 3.37 (Table S3) indicating that the $\mathrm{P}$ is mainly bound via the $\mathrm{sp}^{3}$ carbon sites. Figure $3 \mathrm{c}$ shows that the peaks at 711.2 and $724.8 \mathrm{eV}$ represent the $\mathrm{Fe} 2 \mathrm{p}_{3 / 2}$ and $\mathrm{Fe} 2 \mathrm{p}_{1 / 2}$ spin-orbits with a peak separation of $13.6 \mathrm{eV}$. In addition, two satellite peaks are at 715.5 , and $732.6 \mathrm{eV}$, confirming that $\alpha-\mathrm{Fe}_{2} \mathrm{O}_{3}$ has been deposited on the surface of CMK-3-P support. ${ }^{[33]}$ The different locations of the $\mathrm{Fe} 2 \mathrm{p}$ peaks in $\mathrm{CMK}-3-\mathrm{P}-\mathrm{Fe}_{2} \mathrm{O}_{3}$ and $\mathrm{CMK}-3-\mathrm{Fe}_{2} \mathrm{O}_{3}$ indicate a difference in the electronic properties of $\mathrm{Fe}$ in both materials resulting from SMOSI between the heteroatom-doped CMK-3-P and $\mathrm{Fe}_{2} \mathrm{O}_{3}$ (Figure S12). The fact that such changes of the electronic properties are not becoming apparent in the Mössbauer spectra is showing that these junctions are indeed surface/interface effects rather than bulk phenomena. As shown in Figure 3d, only two P 2p peaks can be seen for CMK-3-P at around 132.6 and $133.7 \mathrm{eV}$, which could be attributed to P-C and P-O bonding, respectively, proving the successful $\mathrm{P}$ incorporation into CMK-3 ${ }^{[34]}$ The total P content determined in CMK-3-P is 7.8 wt.\%. At this point, we exploit density functional theory (DFT) calculation to simulate the initial growth of $\alpha-\mathrm{Fe}_{2} \mathrm{O}_{3}$ nanosplohes on the CMK-3-P support. Figure $3 \mathrm{e}$ proposes the $\mathrm{P}$ bonding configuration, in which $\mathrm{P}$ is covalently bond to $\mathrm{C}$ and $\mathrm{O}$, existing as quinary forms such as $\mathrm{C}$ O- $\mathrm{PO}_{3} \mathrm{H}_{2}, \mathrm{C}-\mathrm{PO}_{3} \mathrm{H}_{2}, \mathrm{C}_{3}-\mathrm{P}, \mathrm{C}_{2}-\mathrm{PO}_{2} \mathrm{H}$ and $\mathrm{C}_{3}-\mathrm{PO}$. As revealed by the DFT calculation results (Figure 3f), the $\mathrm{P}-\mathrm{O}$ species $\mathrm{C}_{3}-\mathrm{PO}$ and $\mathrm{C}_{2}-\mathrm{PO}_{2} \mathrm{H}$ exhibit more negative adsorption energy of 2.25 and $-2.19 \mathrm{eV}$ towards $\mathrm{Fe}^{3+}$ ions, than that of $-1.57 \mathrm{eV}$ for C-P species C3-P. As a result, the P-O species act as anchoring sites for binding of Fe and thus ensure strong metal oxidesupport interactions. After iron loading and calcination, the P $2 p$ region in $\mathrm{CMK}-3-\mathrm{P}-\mathrm{Fe}_{2} \mathrm{O}_{3}$ hybrid has two smaller XPS peaks at 129.5 and $130.4 \mathrm{eV}$ reflecting the presence of iron phosphide species after calcination, giving a direct evidence for strong metal oxide-support interactions (Figure 3d). 

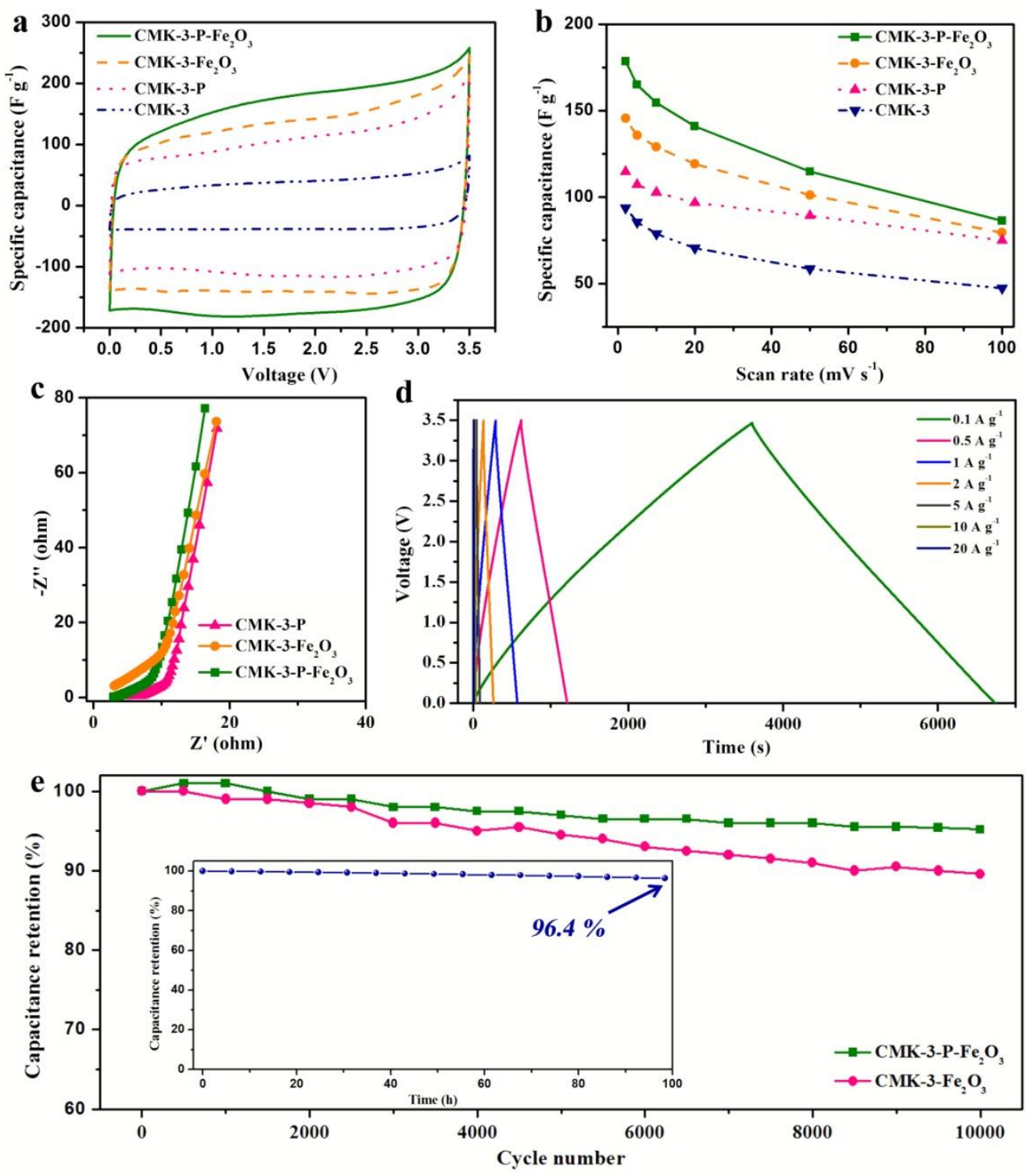

Figure 4 (a) $\mathrm{CV}$ curves at a scan rate of $5 \mathrm{mV} \mathrm{s}^{-1}$, (b) plots of scan rate against the specific capacitance of CMK-3-P-Fe $\mathrm{O}_{3}, \mathrm{CMK}-3-\mathrm{Fe}_{2} \mathrm{O}_{3}, \mathrm{CMK}-3-\mathrm{P}$, and CMK-3. (c) EIS spectra of CMK-3-P-Fe $\mathrm{O}_{3}, \mathrm{CMK}-3-\mathrm{Fe}_{2} \mathrm{O}_{3}$, and CMK-3-P. (d) Galvanostatic charge-discharge curves of CMK-3-P- $\mathrm{Fe}_{2} \mathrm{O}_{3}$-based symmetric supercapacitor at various current densities. (e) Cycling stability of CMK-3-P- $-\mathrm{Fe}_{2} \mathrm{O}_{3}$ and $\mathrm{CMK}-3-\mathrm{Fe}_{2} \mathrm{O}_{3}$ under a constant current density of $5 \mathrm{~A} \mathrm{~g} \mathrm{~g}^{-1}$ (Inset: Voltage holding stability test of the CMK-3-P- $\mathrm{Fe}_{2} \mathrm{O}_{3} / / \mathrm{CMK}-3-\mathrm{P}-\mathrm{Fe}_{2} \mathrm{O}_{3}$ supercapacitor).

The electrochemical performance of CMK-3-P- $\mathrm{Fe}_{2} \mathrm{O}_{3}$ hybrid and the reference materials has first been tested in symmetric supercapacitor devices by using the ionic liquid 1-Ethyl-3methylimidazolium tetrafluoroborate $\left(\mathrm{EMIMBF}_{4}\right)$ as the electrolyte. Cyclic voltammetry $(\mathrm{CV})$ curves of the CMK-3-P-Fe $\mathrm{O}_{3}, \mathrm{CMK}-3-\mathrm{Fe}_{2} \mathrm{O}_{3}, \mathrm{CMK}-3-\mathrm{P}$, and CMK-3 are shown in Figure 4a, S13, S14, and S15. As shown in Figure 4a, all the CV curves show quasi-rectangular 
shapes without distinct redox peaks. The shape of the $\mathrm{CV}$ curves at low scan rates is comparable to previously reported N-doped salt-templated carbons and $\mathrm{N}, \mathrm{S}-\mathrm{CMK}-3 / \mathrm{MnO}_{2}$ composites with a sharp peak arising at $3.5 \mathrm{~V}$, which likely originates from ordering transitions of the IL ions located in the mesopores ${ }^{[22]}$ thus contributing energy stored in the bulk of the IL on top of traditional charge storage in an electric double-layer. ${ }^{[18,19]}$ It was concluded that energy storage in such highly polarizable hybrid electrodes would be further enhanced by maximizing the 3-phase boundary area between CMK-3-P, metal oxide and electrolyte. In consequence, comparison at a fixed scan rate of $20 \mathrm{mV} \mathrm{s}^{-1}$ (Figure S14), reveals that $\mathrm{CMK}-3-\mathrm{P}-\mathrm{Fe}_{2} \mathrm{O}_{3}$ displays the largest specific capacitance among the four materials investigated in spite of the fact that it has the lowest porosity values. Furthermore, the CMK3-P possesses a higher specific capacitance of $114 \mathrm{~F} \mathrm{~g}^{-1}$ than CMK-3 (94 F g ${ }^{-1}$ ), which is due to the enhanced polarity and thus stronger adsorption of electrolyte ions after heteroatom doping. The data suggests a comparable energy storage mechanism in all materials as indicated by the nearly similar shapes of the CV curves independent of the presence or absence of the metal oxide or heteroatoms in the carbon, which is also evident at lower scan rates of $5 \mathrm{mV} \mathrm{s}^{-1}$ (Figure $4 \mathrm{a}$ and $\mathrm{S} 15$ ) but also at scan rates as low as $0.5 \mathrm{mV} \mathrm{s}^{-1}$ (Figure S16). As possibly present reactions that include electron transfer processes are strongly potentialdependent, a proper potential control is important which can be achieved by using a threeelectrode device. Such a device was assembled and oversized CMK-3, polytetrafluoroethylene (PTFE)-bound CMK-3, and CMK-3-P-Fe $\mathrm{O}_{3}$ composite were used as counter electrode, quasi-reference electrode, and working electrode, respectively. The rectangular shape of the CV curve (Figure S17) further demonstrates that redox-type processes do not excessively contribute to the energy storage. This further excludes the presence of redox reactions on the electrode surfaces and underlines the fact that the energy storage in these supercapacitors combines contributions from double-layer formation and ordering transitions into the bulk of the electrolyte. CMK-3-P- $-\mathrm{Fe}_{2} \mathrm{O}_{3}$ shows a bigger slope $0.0533 \mathrm{~A} \mathrm{~s} \mathrm{~g}^{-1} \mathrm{mV}^{-1}$ than that $0.0495 \mathrm{~A} \mathrm{~s} \mathrm{~g}^{-1} \mathrm{mV}^{-1}$ of $\mathrm{CMK}-3-\mathrm{Fe}_{2} \mathrm{O}_{3}$ (Figure $\mathrm{S} 18 \mathrm{c}$ ), demonstrating the enhanced electrolyte adsorption ability for CMK-3-P- $\mathrm{Fe}_{2} \mathrm{O}_{3}$ resulting from the most efficient carbon and oxide polarization due to SMOSI between CMK-3-P support and $\alpha-\mathrm{Fe}_{2} \mathrm{O}_{3}$. As a result, the highest specific capacitance of $179 \mathrm{~F} \mathrm{~g}^{-1}$ is gained at $2 \mathrm{mV} \mathrm{s}^{-1}$ for the $\mathrm{CMK}-3-\mathrm{P}-\mathrm{Fe}_{2} \mathrm{O}_{3}$ (Figure $4 \mathrm{~b}$ ). This would correspond to a capacitance of $\sim 45 \mathrm{~F} / \mathrm{g}$ (only including the mass of the active materials) in a full CMK-3-P- $\mathrm{Fe}_{2} \mathrm{O}_{3} / / \mathrm{CMK}-3-\mathrm{P}-\mathrm{Fe}_{2} \mathrm{O}_{3}$ symmetrical device. When the scan rate increased 50 times, a high capacitance of $86 \mathrm{~F} \mathrm{~g}^{-1}$ was preserved by $\mathrm{CMK}-3-\mathrm{P}-\mathrm{Fe}_{2} \mathrm{O}_{3}$, which has the highest capacity independent of the scan rate. 
Nyquist plots of the electrochemical impedance spectroscopy (EIS) analysis (Figure 4c) in high-frequency region show that the lowest internal resistance of $3.1 \Omega$ is present in the CMK-3-P- $\mathrm{Fe}_{2} \mathrm{O}_{3}$, which is even lower than in the metal-free CMK-3-P, indicating its very high charge transfer capability and strong polarizability. Furthermore, galvanostatic chargedischarge curves of $\mathrm{CMK}-3-\mathrm{P}-\mathrm{Fe}_{2} \mathrm{O}_{3}$ (Figure 4d) and $\mathrm{CMK}-3-\mathrm{Fe}_{2} \mathrm{O}_{3}$ (Figure S19) show typical triangular shapes with linear voltage-time relationship, further indicating the absence of redox processes in the symmetric supercapacitor. The capacitance values calculated for the electrode material from these tests are in good agreement with the values determined from $\mathrm{CV}$ experiments (Figure S20). Our CMK-3-P- $-\mathrm{Fe}_{2} \mathrm{O}_{3}$-based supercapcitor displays high cycling stability above $95 \%$ capacitance retention after 10000 cycles under current density of $5 \mathrm{~A} \mathrm{~g}^{-1}$. This is a more stable cycling performance than that of the $\mathrm{CMK}-3-\mathrm{Fe}_{2} \mathrm{O}_{3}$-based supercapacitor (Figure 4e). However, a voltage floating test (i.e., longer holding time at higher voltage) is generally more meaningful to test the degradation of supercapacitors (such as electrolyte decomposition). ${ }^{[35]}$ Such a stability test was performed from $0-3.5 \mathrm{~V}$ at a current density of $1 \mathrm{~A} \mathrm{~g}^{-1}$ with $6 \mathrm{~h}$ of holding intervals at $3.5 \mathrm{~V}$ before discharge (inset in Figure 4e). The capacitance retention is as high as $96.4 \%$ after 16 of such cycles, indicating the absence of pronounced electrolyte degradation or other irreversible processes. Furthermore, the wellmaintained XRD pattern of CMK-3-P- $\mathrm{Fe}_{2} \mathrm{O}_{3}$ after cycling test (Figure S21), proves its stable structure with the help of covalent $\mathrm{P}-\mathrm{O}-\mathrm{Fe}$ bond between $\alpha-\mathrm{Fe}_{2} \mathrm{O}_{3}$ and CMK-3-P support. 

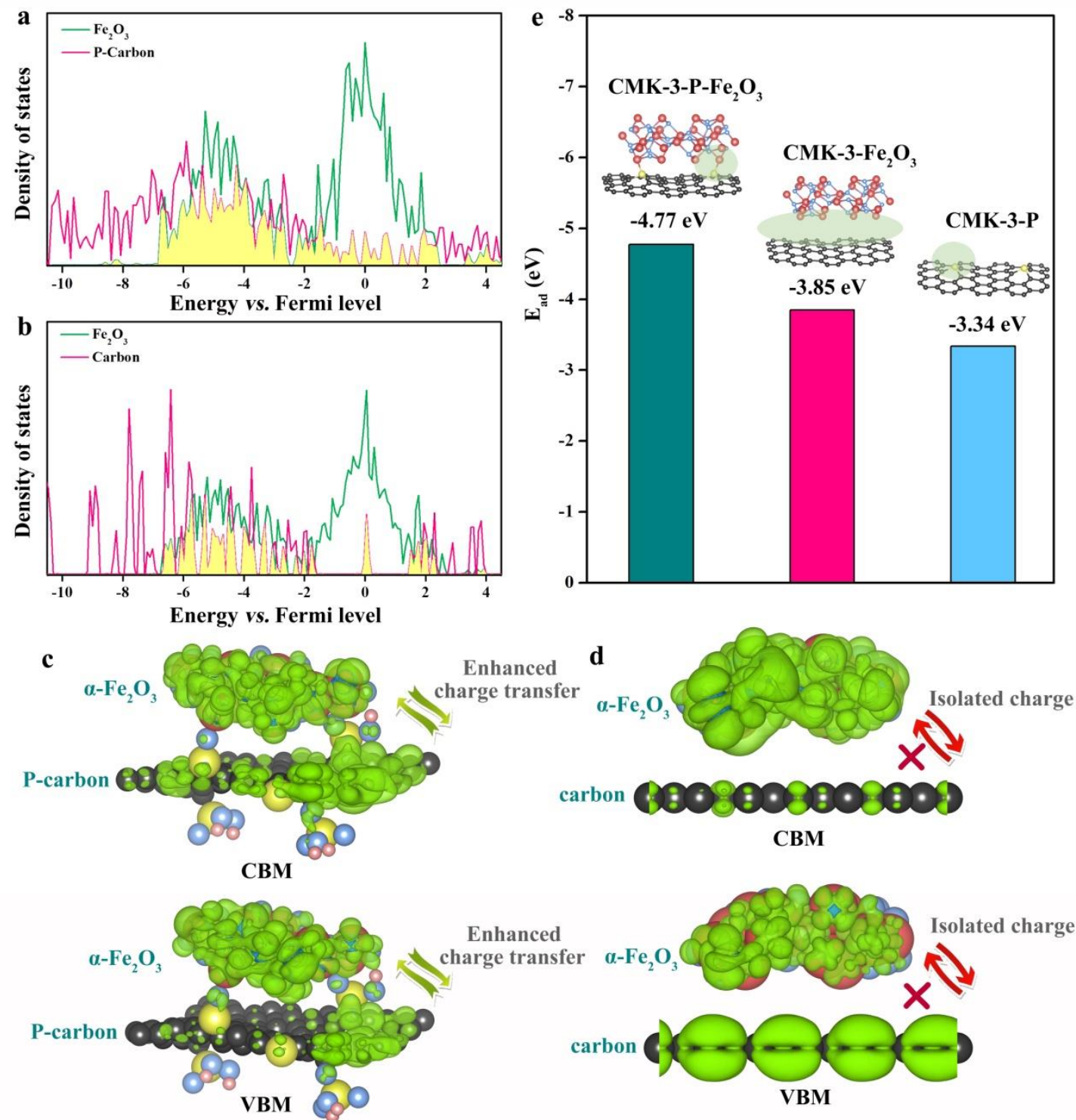

Figure 5. (a, b) Calculated density of states, and (c, d) the distribution of charge density for Pcarbon $/ \alpha-\mathrm{Fe}_{2} \mathrm{O}_{3}$ hybrid with SMOSI of chemical bond, and carbon $/ \alpha-\mathrm{Fe}_{2} \mathrm{O}_{3}$ hybrid with weak metal oxide-support interactions, respectively. (e) Calculated lowest adsorption energy for electrolyte on simulative models of CMK-3-P- $\mathrm{Fe}_{2} \mathrm{O}_{3}, \mathrm{CMK}-3-\mathrm{Fe}_{2} \mathrm{O}_{3}$, and CMK-3-P $\left(\mathrm{BF}_{4}^{-}\right.$ ions are shown here as an example).

To reveal some of the details of the mode of operation of strong metal oxide-support interactions between $\alpha-\mathrm{Fe}_{2} \mathrm{O}_{3}$ and $\mathrm{CMK}-3-\mathrm{P}$ support, density functional theory (DFT) calculations were applied. Here, we establish three simplified simulative models of phosphorus-doped carbon (P-carbon) $/ \alpha-\mathrm{Fe}_{2} \mathrm{O}_{3}$, carbon $/ \alpha-\mathrm{Fe}_{2} \mathrm{O}_{3}$, and $\mathrm{P}$-carbon referred to as CMK-3-P- $-\mathrm{Fe}_{2} \mathrm{O}_{3}, \mathrm{CMK}-3-\mathrm{Fe}_{2} \mathrm{O}_{3}$, and CMK-3-P. In the comparison, we found a larger overlap area in the density of states between $\mathrm{Fe}_{2} \mathrm{O}_{3}$ and P-carbon (Figure 5a) than that between $\mathrm{Fe}_{2} \mathrm{O}_{3}$ and non-doped carbon (Figure 5b). This indicates that the P-carbon $/ \alpha-\mathrm{Fe}_{2} \mathrm{O}_{3}$ exhibits a 
stronger electron coupling and exchange at the phase boundary than carbon $/ \alpha-\mathrm{Fe}_{2} \mathrm{O}_{3}$. With the help of these SMOSI, the charge transport between $\alpha-\mathrm{Fe}_{2} \mathrm{O}_{3}$ phase and $\mathrm{P}$-carbon support is enhanced as the conduction band minimum (CBM) and valence band maximum (VBM) show in Figure 5c. On the other hand, due to the weak metal oxide-support interactions, the charge would distribute on each $\alpha-\mathrm{Fe}_{2} \mathrm{O}_{3}$ phase and carbon support independently in carbon $/ \alpha-\mathrm{Fe}_{2} \mathrm{O}_{3}$ (Figure 5d and Figure S22). As a result, the CMK-3-P- $-\mathrm{Fe}_{2} \mathrm{O}_{3}$ shows a lower resistance than CMK-3- $-\mathrm{Fe}_{2} \mathrm{O}_{3}$, attributing to the well-formed $\mathrm{CMK}-3-\mathrm{P}-\mathrm{Fe}_{2} \mathrm{O}_{3}$ hybrid as an integral whole with strong junction between the phases. The P heteroatoms not only strengthen interactions but also cause a more negative electrolyte adsorption energy of $-4.77 \mathrm{eV}$ on the edge of CMK3-P- $\mathrm{Fe}_{2} \mathrm{O}_{3}$ than that $-3.85 \mathrm{eV}$ and $-3.34 \mathrm{eV}$ of $\mathrm{CMK}-\mathrm{Fe}_{2} \mathrm{O}_{3}$ and $\mathrm{CMK}-3-\mathrm{P}$ (Figure 5e). To our best knowledge, it can be regarded as thousands of "energy depression" in CMK-3-P- $\mathrm{Fe}_{2} \mathrm{O}_{3}$ hybrid to catch electrolyte ions stronger, thus leading to its higher energy/power density.

In summary, we have demonstrated that a phosphorus-doped mesoporous carbon (CMK-3-P)$\mathrm{Fe}_{2} \mathrm{O}_{3}$ hybrid comes with stronger metal oxide-support interaction than a non-doped analogue. The successful P heteroatom incorporation not only leads to covalent bonding and thus more efficient junction between carbon and metal oxide but also to enhanced interaction with the electrolyte ions and thus higher energy storage. As a result, the obtained $\mathrm{CMK}-3-\mathrm{P}-\mathrm{Fe}_{2} \mathrm{O}_{3}$ is highly polarizable and has a lower resistance for fast electron transport, and more active sites for extraordinary strong electrolyte adsorption ability at the carbon-metal oxide boundaries, which is not of the same enthalpy in the non-doped carbon support. Independent of the presence of heteroatoms or metal oxides, the energy storage mechanism into the electrodes is apparently similar and combines contributions from double-layer formation and ordering transitions into the bulk of the electrolyte. This further reveals that specific surface area and microporosity are not the solely contributors that have to be optimized for efficient energy storage. Our study may open a general route for further enhancement of energy density of ILbased supercapacitors and related devices by tailoring the electron density distribution at the phase boundary between carbon, metal oxide and electrolyte. Hence, in order to make efficient use of these alternative energy storage terms in supercapacitors, a variety of structural parameters including (but not limited to) the metal oxide loading/particle size, the carbon pore structure and polarity, and the ionic liquid itself have to be carefully balanced and optimized in future work. 


\section{Conflicts of interests}

The authors declared no conflicts of interests.

\section{Data availability}

The raw/processes data required to reproduce these findings cannot be shared at this time due to technical or time limitations. Data will be made available by the corresponding author upon request.

\section{References}

[1] F. Beguin, V. Presser, A. Balducci, E. Frackowiak, Carbons and Electrolytes for Advanced Supercapacitors, Adv. Mater. 26 (2014) 2219-2251.

[2] P. Simon, Y. Gogotsi, Materials for electrochemical capacitors, Nat. Mater. 7 (11) (2008) 845-854.

[3] M. Salanne, B. Rotenberg, K. Naoi, K. Kaneko, P.-L. Taberna, C.P. Grey, B. Dunn, P. Simon, Efficient Storage Mechanisms for Building Better Supercapacitors, Nat. Energy 1 (2016) 16070.

[4] W.T. Gu, G. Yushin, Review of Nanostructured Carbon Materials for Electrochemical Capacitor Applications: Advantages and Limitations of Activated Carbon, Carbide-Derived Carbon, Zeolite-Templated Carbon, Carbon Aerogels, Carbon Nanotubes, Onion-Like Carbon, and Graphene, Wiley Interdiscip. Rev. Energy Environ. 3 (2014) 424-473.

[5] F.L. Lai, Y.E. Miao, L.Z. Zuo, H.Y. Lu, Y.P. Huang, T.X. Liu, Biomass-Derived Nitrogen-Doped Carbon Nanofiber Network: A Facile Template for Decoration of Ultrathin Nickel-Cobalt Layered Double Hydroxide Nanosheets as High-Performance Asymmetric Supercapacitor Electrode, Small 12 (2016) 3235-3244.

[6] Y.W. Zhu, S. Murali, M.D. Stoller, K.J. Ganesh, W.W. Cai, P.J. Ferreira, A. Pirkle, R.M. Wallace, K.A. Cychosz, M. Thommes, D. Su, E.A. Stach, R.S. Ruoff, Carbon-Based Supercapacitors Produced by Activation of Graphene, Science 332 (2011) 1537-1541.

[7] Y. Gogotsi, P. Simon, True Performance Metrics in Electrochemical Energy Storage, Science 334 (2011) 917-918.

[8] L. Borchardt, M. Oschatz, S. Kaskel, Tailoring Porosity in Carbon Materials for Supercapacitor Applications, Mater. Horiz. 1 (2014) 157-168.

[9] W. Zong, F.L. Lai, G.J. He, J.R. Feng, W. Wang, R.Q. Lian, Y.E. Miao, G.C. Wang, I.P. Parkin, T.X. Liu, Sulfur-Deficient Bismuth Sulfide/Nitrogen-Doped Carbon Nanofibers as Advanced Free-Standing Electrode for Asymmetric Supercapacitors, Small 14 (2018) 1801562.

[10] A. Slesinski, C. Matei-Ghimbeu, K. Fic, F. Béguin, E. Frackowiak, Self-Buffered pH at Carbon Surfaces in Aqueous Supercapacitors, Carbon 129 (2018) 758-765.

[11] Q. Abbas, P. Babuchowska, E. Frackowiak, F. Béguin, Sustainable AC/AC Hybrid Electrochemical Capacitors in Aqueous Electrolyte Approaching the Performance of Organic Systems, J. Power Sources 326 (2016) 652-659.

[12] S. Boukhalfa, D. Gordon, L. He, Y.B. Melnichenko, N. Nitta, A. Magasinski, G. Yushin, In Situ Small Angle Neutron Scattering Revealing Ion Sorption in Microporous Carbon Electrical Double Layer Capacitors, ACS Nano 8 (2014) 2495-2503. 
[13] C. Portet, Z. Yang, Y. Korenblit, Y. Gogotsi, R. Mokaya, G. Yushin, Electrical DoubleLayer Capacitance of Zeolite-Templated Carbon in Organic Electrolyte, J. Electrochem. Soc. 156 (2009) A1-A6.

[14] J. Chmiola, G. Yushin, Y. Gogotsi, C. Portet, P. Simon, P.L. Taberna, Anomalous Increase in Carbon Capacitance at Pore Sizes Less than 1 Nanometer, Science 313 (2006) 1760-1763.

[15] P. Simon, Y. Gogotsi, Capacitive Energy Storage in Nanostructured CarbonElectrolyte Systems, Acc. Chem. Res. 46 (2013) 1094-1103.

[16] M. Armand, F. Endres, D.R. MacFarlane, H. Ohno, B. Scrosati, Ionic-Liquid Materials for the Electrochemical Chanllenges of the Futures, Nat. Mater. 8 (2009) 621-629.

[17] A. Brandt, S. Pohlmann, A. Varzi, A. Balducci, S. Passerini, Ionic Liquids in Supercapcitiors, MRS Bull. 38 (2013) 554-559.

[18] R.Y. Yan, M. Antonietti, M. Oschatz, Towards the Experimental Understanding of the Energy Storage Mechanism and Ion Dynamics in Ionic Liquid Based Supercapacitors, Adv. Energy Mater. 8 (2018) 1800026.

[19] M. Antonietti, X. Chen, R. Yan, M. Oschatz, Sroring Electricity as Chemical Energy: Beyond Traditional Electrochemistry and Double-Layer Compression, Energy Environ. Sci. 11 (2018) 3069-3074.

[20] B. Rotenberg, M. Salanne, Structural Transitions at Ionic Liquid Interfaces, J. Phys. Chem. Lett. 6 (2015) 4978-4985.

[21] R. Futamura, T. Liyama, Y. Takasaki, Y. Gogotsi, M.J. Biggs, M. Salanne, J. Ségalini, P. Simon, K. Kaneko, Partial Breaking of the Coulombic Ordering of Ionic Liquids Confined in Carbon Nanopores, Nat. Materials 16 (2017) 1225-1232.

[22] F.L. Lai, J.R. Feng, R.Y. Yan, G. C. Wang, M. Antonietti, M. Oschatz, Breaking the Limits of Ionic Liquid-Based Supercapacitors: Mesoporous Carbon Electrodes Functionalized with Manganese Oxide Nanosplotches for Dense, Stable, and Wide-Temperature Energy Storage, Adv. Funct. Mater. 28 (2018) 1801298.

[23] S.X. Sun, J.W. Lang, R.T. Wang, L.B. Kong, X.C. Li, X.B. Yan, Identifying Pseudocapacitance of $\mathrm{Fe}_{2} \mathrm{O}_{3}$ in an Ionic Liquid and its Application in Asymmetric Supercapacitors, J. Mater. Chem. A 2 (2014) 14550-14556.

[24] Q.T. Qu, S.B. Yang, X.L. Feng, 2D Sandwich-Like Sheets of Iron Oxide Grown on Graphene as High Energy Anode Material for Supercapacitor, Adv. Mater. 23 (2011) 55745580.

[25] H.W. Wang, Z.J. Xu, H. Yi, H.G. Wei, Z.H. Guo, X.F. Wang, One-Step Preparation of Single-Crystalline $\mathrm{Fe}_{2} \mathrm{O}_{3}$ Particles/Graphene Composite Hydrogels as High Performance Anode Materials for Supercapacitors, Nano Energy 7 (2014) 86-96.

[26] J. Zhao, Z.J. Li, X.C. Yuan, Z. Yang, M. Zhang, A.L. Meng, Q.D. Li, A High-Energy Density Asymmetric Supercapacitor Based on $\mathrm{Fe}_{2} \mathrm{O}_{3}$ Nanoneedle Arrays and $\mathrm{NiCo}_{2} \mathrm{O}_{4} / \mathrm{Ni}(\mathrm{OH})_{2}$ Hybrid Nanosheet Arrays Grown on SiC Nanowire Networks as FreeStanding Advanced Electrodes, Adv. Energy Mater. 8 (2018) 1702787.

[27] S. Kumar, G. Saeed, N.H. Kim, J.H. Lee, Hierarchical Nanohoneycomb-Like CoMoO $4^{-}$ $\mathrm{MnO}_{2}$ Core-Shell and $\mathrm{Fe}_{2} \mathrm{O}_{3}$ Nanosheet Arrays on 3D Graphene Foam with Excellent Supercapacitive Performance, J. Mater. Chem. A 6 (2018) 7182-7193.

[28] S. Rudra, A.K. Nayak, S. Koley, R. Chakraborty, P.K. Maji, M. Pradhan, RedoxMediated Shape Transformation of $\mathrm{Fe}_{3} \mathrm{O}_{4}$ Nanoflakes to Chemically Stable $\mathrm{Au}-\mathrm{Fe}_{2} \mathrm{O}_{3}$ Composite Nanorods for a High-Performance Asymmetric Solid-State Supercapacitor Device, ACS Sustainable Chem. Eng. 7 (2019) 724-733.

[29] H.J. Shin, R. Ryoo, M. Kruk, M. Jaroniec, Modification of SBA-15 Pore Connectivity by High-Temperature Calcination Investigated by Carbon Inverse Replication, Chem. Commun. 4 (2001) 349-350. 
[30] L.B. Wang, H.L. Yang, X.X. Liu, R. Zeng, M. Li, Y.H. Huang, X.L. Xu, Constructing Hierarchical Tectorum-Like Alpha- $\mathrm{Fe}_{2} \mathrm{O}_{3} / \mathrm{PPy}$ Nanoarrays on Carbon Cloth for Solid-State Asymmetric Supercapacitors, Angew. Chem. Int. Ed. 56 (2017) 1105-1110.

[31] F. Yang, X.X. Fan, C.X. Wang, W. Yang, L.Q. Hou, X.W. Xu, A.D. Feng, S. Dong, K. Chen, Y. Wang, Y.F. Li, P-Doped Nanomesh Graphene with High-Surface-Area as An Efficient Metal-Free Catalyst for Aerobic Oxidative Coupling of Amines, Carbon 121 (2017) 443-451.

[32] Z.J. Liu, Z.H. Zhao, Y.Y. Wang, S. Dou, D.F. Yan, D.D. Liu, Z.H. Xia, S.Y. Wang, In Situ Exfoliated, Edge-Rich, Oxygen-Functionalized Graphene from Carbon Fibers for Oxygen Electrocatalysis, Adv. Mater. 29 (2017) 1606207.

[33] P. Zhang, T. Wang, X.X. Chang, L. Zhang, H.L. Gong, Synergistic Cocatalytic Effect of Carbon Nanodots and $\mathrm{Co}_{3} \mathrm{O}_{4}$ Nanoclusters for the Photoelectrochemical Water Oxidation on Hematite, Angew. Chem. Int. Ed. 55 (2016) 5851-5855.

[34] Y.J. Tang, M.R. Gao, C.H. Liu, S.L. Li, H.L. Jiang, Y.Q. Lan, M. Han, S.H. Yu, Porous Molybdenum-Based Hybrid Catalysts for Highly Efficient Hydrogen Evolution, Angew. Chem. Int. Ed. 54 (2015) 12928-12932.

[35] D. Weingarth, A. Foelske-Schmitz, R. Kötz, Cycle Versus Voltage Hold-Which Is the Better Stability Test for Electrochemical Double Layer Capacitors?, J. Power Sources 225 (2013) 84-88. 